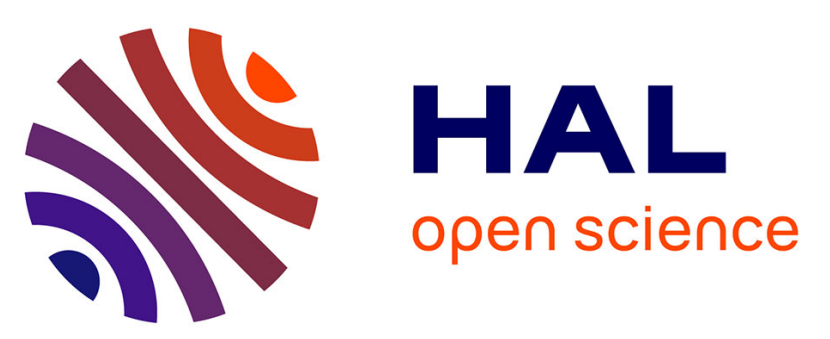

\title{
Biomagnification of perfluoroalkyl acids (PFAAs) in the food web of an urban river: assessment of the trophic transfer of targeted and unknown precursors and implications
}

Caroline Simonnet-Laprade, Hélène Budzinski, Kévin Maciejewski, Karyn Le

Menach, Fabrice Alliot, Aurélie Goutte, Pierre Labadie, Raphaël Santos

\section{To cite this version:}

Caroline Simonnet-Laprade, Hélène Budzinski, Kévin Maciejewski, Karyn Le Menach, Fabrice Alliot, et al.. Biomagnification of perfluoroalkyl acids (PFAAs) in the food web of an urban river: assessment of the trophic transfer of targeted and unknown precursors and implications. Environmental Science: Processes \& Impacts, 2019, 10.1039/C9EM00322C . hal-02282813

\section{HAL Id: hal-02282813 https://hal.science/hal-02282813}

Submitted on 10 Sep 2019

HAL is a multi-disciplinary open access archive for the deposit and dissemination of scientific research documents, whether they are published or not. The documents may come from teaching and research institutions in France or abroad, or from public or private research centers.
L'archive ouverte pluridisciplinaire HAL, est destinée au dépôt et à la diffusion de documents scientifiques de niveau recherche, publiés ou non, émanant des établissements d'enseignement et de recherche français ou étrangers, des laboratoires publics ou privés. 


\title{
Biomagnification of perfluoroalkyl acids (PFAAs) in the food web of
}

\section{an urban river: assessment of the trophic transfer of targeted and}

\section{unknown precursors and implications}

\author{
Caroline Simonnet-Laprade ${ }^{1}$, Hélène Budzinski ${ }^{2}$, Kevin Maciejewski ${ }^{1}$, Karyn Le Menach², Raphaël \\ Santos $^{3}$, Fabrice Alliot ${ }^{4}$, Aurélie Goutte ${ }^{4}$, Pierre Labadie $^{2 *}$
}

\footnotetext{
${ }^{1}$ Université de Bordeaux, EPOC, UMR 5805, F-33400 Talence, France

${ }^{2}$ CNRS, EPOC, UMR 5805, F-33400 Talence, France

${ }^{3}$ HEPIA, Western Switzerland University of Applied Sciences, Ecology and Engineering of Aquatic systems research group, $\mathrm{CH}-1254$ Jussy, Switzerland.

${ }^{4}$ UMR 7619 METIS, EPHE/UPMC/CNRS, PSL Research University, F-75005, Paris, France

*Corresponding author. Contact: pierre.labadie@u-bordeaux.fr
}

Environmental Science: Processes \& Impacts, 2019, PFAS themed issue

DOI: 10.1039/C9EM00322C 


\section{Abstract}

The present work examined the trophic transfer of perfluoroalkyl and polyfluoroalkyl substances (PFASs) in a typical urban river (Orge River, near Paris, France), and aimed to investigate the potential contribution of precursors to the biomagnification of perfluoroalkyl acids (PFAAs). Sixteen PFAAs, twelve of their precursors (pre-PFAAstargeted) and two fluorinated alternatives to long-chain PFASs were analyzed in water, sediments and biota (including biofilm, invertebrates and fish). Twenty two compounds were detected in biological samples (2.0-147 $\mathrm{ng} \mathrm{g}^{-1}$ wet weight), perfluorooctane sulfonate (PFOS) and $\mathrm{C}_{12}-\mathrm{C}_{14}$ perfluoroalkyl carboxylates (PFCAs) being predominant while $\sum$ prePFAAs targeted contributed to $1-18 \%$ of $\sum$ PFASs. Trophic magnification factors (TMFs) were $>1$ (i.e. denoting biomagnification) for $\mathrm{C}_{9}-\mathrm{C}_{14}$ PFCAs, $\mathrm{C}_{7}-\mathrm{C}_{10}$ perfluoroalkyl sulfonates (PFSAs) and several prePFAAs (e.g. 8:2 and 10:2 fluorotelomer sulfonates). The significant decrease in $\sum$ pre-PFCAs/ 2 PFCAs concentration ratio with trophic level suggested a likely contribution of selected precursors to the biomagnification of PFCAs through biotransformation, while this was less obvious for PFOS. The Total Oxidizable Precursor assay, applied for the first time to sediment and biota, revealed the presence of substantial proportions of extractable unknown pre-PFAAs in all samples (i.e. $15-80 \%$ of $\sum$ PFASs upon oxidation). This proportion significantly decreased from sediments to invertebrates and fish, thereby pointing to the biotransformation of unattributed pre-PFAAs in the trophic web, which likely contributes to the biomagnification of some PFAAs (i.e. $C_{9}-C_{12}$ PFCAs and $C_{7}-C_{10}$ PFSAs). 


\section{Introduction}

Perfluoroalkyl carboxylates (PFCAs) and sulfonates (PFSAs) are of major environmental concern because of their ubiquitous occurrence, persistence and toxicity ${ }^{1}$. These chemicals, used as additives and surfactants in a large number of industrial applications and manufactured products, can be introduced into the environment following their production, their use and their disposal, either directly or indirectly via the degradation of precursors ${ }^{2}$. Their worldwide presence in aquatic wildlife was reported since the early $2000 \mathrm{~s}^{3,4}$. and long-chain perfluoroalkyl acids (PFAAs) (i.e. PFCAs with carbon number $n_{c}>8$ and PFSAs with $n_{c}>6$ ) are recognized as bioaccumulative substances ${ }^{4}$.

Exposure to PFASs can occur via direct and dietary uptake. High PFAS levels reported in aquatic mammals from remote areas suggest the major role of the trophic pathway ${ }^{3}$. Biomagnification factors (BMFs) and trophic magnification factors (TMFs) are field-based metrics relevant to assess the biomagnification potential of a contaminant ${ }^{5}$. BMFs and TMFs $>1$ have been consistently reported for PFOS and long-chain PFCAs in marine, lake or estuarine food webs, providing evidence for their biomagnification ${ }^{6-11}$. However, data showed a considerable study-to-study variability that may be explained by factors such as sampling design, taxa and ecosystem properties, statistical data processing and, possibly, the biotransformation of precursors ${ }^{12}$.

Numerous PFASs are less persistent than PFCAs or PFSAs and may be converted into PFAAs in the environment. Identified PFAA precursors (pre-PFAAs) include for instance (alkyl-)perfluoroalkyl sulfonamides ((alkyl-)FASAs) ${ }^{13-15}$, (alkyl-) perfluoroalkyl sulfonamidoacetic acids ((alkyl-)FASAAs) ${ }^{2}$ or polyfluoroalkyl phosphoric acid diesters (diPAPs) ${ }^{16}$. Gebbink et al., ${ }^{17}$ proposed that precursors could play a significant role in the biomagnification of PFCAs in fish from the Baltic Sea and species-specific biotransformation of pre-PFAAs was suggested in fish from the Rhône River ${ }^{18}$. Additional pre-PFAAs including fluorotelomer sulfonates (FTSAs) previously detected in aquatic ecosystems ${ }^{19,20}$, could also contribute to the biomagnification of PFAAs, since their biotransformation can lead to the production of PFCA homologues ${ }^{21-23}$. However, like that of diPAPs, their trophic transfer in aquatic ecosystems 
has been little investigated so far. Such pre-PFAAs may originate from numerous sources and urban rivers are considered as a major receptacle for these chemicals ${ }^{24}$.

The present study addressed the trophodynamics of PFASs in an urban river and it specifically focused on the potential contribution of a wide range of pre-PFAAs to the biomagnification of PFAAs. Water, sediment, and biota samples (including biofilm, invertebrates and fish) were collected in the Orge River (France), previously identified as a hotspot of PFAS contamination at French nationwide level ${ }^{25}$. Thirty PFASs were analyzed including PFCAs, PFSAs and numerous pre-PFAAs such as FTSAs, (alkyl-)FASAs, (alkyl-)FASAAs and diPAPs. The levels of two per- and polyfluoroalkyl ethers (PFPEs), HFPO-DA (namely GenX) and ADONA, were also determined to provide additional knowledge on the presence and behavior of these emerging PFASs used as alternative to long-chain PFAAs ${ }^{26}$. In addition, the occurrence of unknown pre-PFAAs was indirectly estimated using the Total Oxidisable Precursor (TOP) assay, originally developed to convert pre-PFAAs into PFCAs in urban runoff samples ${ }^{27}$. This approach proved relevant to demonstrate the presence of unknown pre-PFAAs in wastewater, ground water and soils samples ${ }^{27-31}$. In the present work, the TOP assay was applied for the first time to biota and sediment samples to test the hypothesis that unknown pre-PFAAs contribute to the biomagnification of PFASs, which was estimated through the calculation of field-metrics such as BMFs and TMFs.

\section{Materials and methods}

\subsection{Sampling}

Sampling was performed in September 2016, along a 500 m-transect on the Orge River at ViryChâtillon, a few kilometers upstream of the confluence with the Seine River $\left(48^{\circ} 40^{\prime} 23^{\prime \prime} \mathrm{N} ; 2^{\circ} 21^{\prime} 30^{\prime \prime} \mathrm{E}\right)$ (Figure S1 of the Electronic Supporting information (ESI)). This medium-sized river (mean flow rate $\approx 5$ $\left.\mathrm{m}^{3} \cdot \mathrm{s}^{-1}\right)$ receives both sewage discharge and urban runoff ${ }^{32}$. 
Samples ( $n=29$, Table S1)) of eight fish species were collected by electrofishing: barbel Barbus barbus, European bullhead Cottus gobio, roach Rutilus rutilus, gudgeon Gobio gobio, common perch Perca fluviatilis, Pumpkinseed Leopmis gibbosus, bullhead catfish Ameiurus melas and tench Tinca tinca. Such sampling strategy allowed the collection of species with supposedly contrasted feeding behavior (i.e. benthic vs bentho-pelagic, omnivorous vs carnivorous...). The permit for the capture of fish for scientific purposes was delivered by local authorities (Departmental Direction of Territories). Fish were identified, anesthetized (tricaine methanesulfonate, $1 \mathrm{~g} \mathrm{~L}^{-1}$ in river water), euthanized on the field and transferred into aluminium trays kept at $4^{\circ} \mathrm{C}$. Once in the laboratory, they were measured, weighted and stored at $-20^{\circ} \mathrm{C}$; the smallest individuals of each taxa were pooled (Table S1) while the others were processed individually.

Invertebrates were collected with a surber net and both poor diversity and population density were observed. Therefore, only four taxa could be collected and composite samples were obtained as follows: lymneae $(n=3)$, gammaridae $(n=3)$, notonectidae $(n=1)$ and corbiculidae $(n=1)$. Two samples of the macrophyte Ranunculus pseudofluitans, two periphytic biofilm samples and two leaf litter samples were also collected. Overall, 43 biological samples representative of the whole trophic web were collected, a number that is reasonable for TMF assessment ${ }^{5}$.

In addition, three composite surface sediment samples $(0-2 \mathrm{~cm})$ were taken along a $100 \mathrm{~m}$-transect (Figure S1) with a stainless steel spoon. All samples were transported in aluminum trays kept at $4^{\circ} \mathrm{C}$ in the field, then stored at $-20^{\circ} \mathrm{C}$. Surface water was collected in a 1 L-HDPE bottle $(n=1)$; an aliquot was filtered on GF/F filters to determine the suspended matter content $\left(15.7 \mathrm{mg} \mathrm{L}^{-1}\right)$.

\subsection{Compounds and reagents}

Thirty PFASs were analyzed: eleven PFCAs $\left(C_{4}-C_{14}\right)$, five PFSAs $\left(C_{4}, C_{6}-C_{8}\right.$ and $\left.C_{10}\right)$, four FTSAs $(4: 2,6: 2$, 8:2 and 10:2 FTSA), three (alkyl-)FASAs (FOSA, MeFOSA, EtFOSA), three (alkyl-)FASAAs (FOSAA, MeFOSAA, EtFOSAA), two diPAPs (6:2 and 8:2 diPAP) and two per- and polyfluoroalkyl ethers PFPEs 
(ADONA and HFPO-DA) (see Table S2 for details, including internal standards (ISs)). Standard solutions (chemical purity > 98\%) were acquired from Wellington Laboratories (via BCP Instruments, Irigny, France). A full list of chemicals and solvents is provided in the ESI.

\subsection{Sample preparation, extraction and analysis}

Biota samples were freeze-dried, ground and homogenized prior to analysis. Sediments were also freeze-dried, sieved at $2 \mathrm{~mm}$ and homogenized.

Biota samples were processed using a previously published method ${ }^{11}$ : microwave-assisted extraction was performed on $0.2 \mathrm{~g}$-samples (dry weight, $\mathrm{dw}$ ) with $12 \mathrm{~mL}$ of $\mathrm{MeOH}+0.2 \% \mathrm{NH}_{4} \mathrm{OH}$ and followed by Strata X-AW/graphitized carbon clean-up. Sediment samples were processed similarly but clean-up was performed using graphite only. Unfiltered water samples $(100 \mathrm{~mL})$ were concentrated using solid phase extraction on Strata X-AW cartridges ${ }^{19}$. Extracts were evaporated to $300 \mu \mathrm{L}$ under a nitrogen stream and stored at $-20^{\circ} \mathrm{C}$ prior to analysis. ISs ( $1 \mathrm{ng}$ each) were added the beginning of the extraction procedure in samples, procedural blanks and spiked control samples.

PFAS analysis was carried out by liquid chromatography coupled with tandem mass spectrometry using a 1200 LC system and a 6490 triple quadrupole mass spectrometer from Agilent Technologies (Massy, France); the electrospray ionization source was operated in negative mode ${ }^{11}$. Further details are provided in the ESI. Note that sum-branched (Br-PFOS) and linear PFOS (L-PFOS) were quantified separately using the calibration curve of L-PFOS.

\subsection{Total Oxidizable Precursor (TOP) assay}

The principle of the TOP assay has previously been published ${ }^{31}$. Briefly, extracts are exposed to hydroxyl radicals generated by the thermolysis of persulfate under basic $\mathrm{pH}$ conditions, to promote the conversion of pre-PFAAs into PFCAs of similar or shorter perfluoroalkyl chain length. 
The TOP assay was applied to sediment and water samples; due to sample availability, a limited set of selected biota samples $(n=15)$ were also treated with this method. For water samples, the oxidation procedure was adapted from Houtz and Sedlak ${ }^{27}$ : samples were amended with persulfate $(60 \mathrm{mM})$ and $\mathrm{NaOH}(150 \mathrm{mM})$ and incubated at $85^{\circ} \mathrm{C}$ for $6 \mathrm{~h}$. To prevent their oxidation, ISs (4 ng each) were added after sample cooling and $\mathrm{pH}$ neutralization with $\mathrm{HCl}(3 \mathrm{M})$; samples were subsequently extracted as described in the previous section. The biota and sediment extract oxidation procedure was adapted from Houtz et al. ${ }^{28}$. After microwave extraction $\left(\mathrm{MeOH}+0.2 \% \mathrm{NH}_{4} \mathrm{OH}\right)$ and graphite clean-up, extracts were concentrated to $100 \mu \mathrm{L}$, transferred into $125 \mathrm{~mL}$-HDPE bottles and evaporated to dryness. Then, $100 \mathrm{~mL}$ of ultra-pure water containing $60 \mathrm{mM}$ of persulfate and $150 \mathrm{mM}$ of $\mathrm{NaOH}$ were added to each bottle; sonication (20 $\mathrm{min}$ ) was performed to promote the dissolution of PFASs. Samples were then processed as described above for water samples.

The sum of pre-PFAAs targeted in this study (i.e. FTSAs, (alkyl-)FASAs, (alkyl-)FASAAs and diPAPs) was thereafter termed $\sum$ pre-PFAAs $s_{\text {targeted. }}$ TOP assay data were used to calculate the increase of $\sum$ PFCAs after oxidation (noted thereafter $\triangle \mathrm{PFCAs}$, expressed on a molar basis), which allowed to estimate the total extractable amount of pre-PFAAs ( $\sum$ pre-PFAAstotal) in each sample (see ESI for calculation details). Based on these results, the fraction of unidentified precursors ( $\sum$ pre-PFAAs unknown) could be determined for each sample treated with the TOP assay, i.e. $\sum$ pre-PFAAs unknown $_{n}=\sum$ pre-PFAAs $_{\text {total }}-\sum$ pre-PFAAs $s_{\text {targeted }}$.

\subsection{Stable isotope analysis}

The isotopic composition of biota samples ( $\mathrm{C}$ and $\mathrm{N}$ ) was evaluated on defatted samples ${ }^{33}$ while carbonates were removed from sediments with diluted $\mathrm{HCl}$. Analysis was performed on $0.2( \pm 0.1) \mathrm{mg}$ of matrix using a ThermoFinnigan Delta V EA-IRMS with a Conflo IV interface. Carbon and nitrogen isotope compositions were expressed as per mil (\%o) in the $\delta$ notation relative to Vienna PeeDee Belemnite (VPDB) and atmospheric $\mathrm{N}_{2}$, respectively. The reproducibility (i.e. the relative standard 
deviation of triplicate analyses performed on selected samples), was less than $5 \%$. Trueness was determined using reference materials: IAEA-N2 $\left(\delta^{15} \mathrm{~N}=20.3 \%\right.$ \% $0.2 \%$ ) and USG-24 $\left(\delta^{13} \mathrm{C}=-16.1 \pm\right.$ $0.2 \%$ \%). Experimental results were in good agreement with certified values and averaged $20.59 \pm$ $0.07 \%$ o $(n=15)$ and $-15.82 \pm 0.26 \%(n=28)$ for IAEA-N2 and USG-24, respectively.

\section{6. $\underline{Q A / Q C}$}

$\mathrm{C}_{4}-\mathrm{C}_{12}$ PFCAs, PFOS and diPAPs were frequently detected at trace level in procedural blanks (Table S4). Blank correction was performed when applicable and the Limit of Detection (LOD) was determined as the standard deviation of the blanks multiplied by the $t_{n-1,95}$ Student coefficient ${ }^{19}$. For analytes not detected in the blanks, LODs were determined as the concentration yielding a signal to noise ratio of 3. Overall, LODs in water, sediments and biota were in the range $0.003-0.34 \mathrm{ng} \mathrm{L}^{-1}, 0.014-0.35 \mathrm{ng} \mathrm{g}^{-1}$ $\mathrm{dw}$ and $0.005-0.21 \mathrm{ng} \mathrm{g}^{-1}$ wet weight (ww), respectively (Table S5).

Regarding the targeted analysis, reproducibility was lower than $10 \%$ except for $8: 2$ diPAP in water samples (28\%). For this compound, qualitative water concentration data are given, for information only. Accuracy ranged between 80 and 120\% except for PFHpS (128-138\%), 10:2 FTSA (52-79\%), EtFOSAA (111-123\%) and 8:2 diPAP (132-139\%); the concentration of these four analytes in samples were corrected according to their mean accuracy value (Table S6). Method trueness was controlled through the analysis of NIST SRM 1947 reference samples (Lake Michigan Trout Tissue, $n=4$ ) (Table S7) and PFAS concentrations were in good agreement with previous reports ${ }^{34}$.

Full details on the TOP assay validation are given in the "QA/OC" and "TOP assay" sections of the ESI (e.g. extraction efficiencies, conversion rates, oxidation product patterns...). Overall, acceptable analyte recovery rates were achieved (Table S6) and the complete conversion of pre-PFAAstargeted was observed for all sample extracts. 


\subsection{Statistical analysis and TMF/BMF calculation}

Since data were not normally distributed, statistical differences between two or several groups were conducted using either the Mann-Whitney or the Kruskal-Wallis tests, using the "R commander" package for R statistical software ( $R$ version 3.3.3, R core team 2017). The Spearman's rank correlation coefficient was used to investigate correlation between variables. The difference in PFCA concentrations before and after oxidation were conducted using the paired samples Wilcoxon Test. For all tests, significance was set at $p \leq 0.05$. Hierarchical clustering based on Ward's minimum variance classification and Euclidian distance methods was performed using RcmdrPlugin.FactoMiner (function hclust) to identify pattern similarity of PFCAs formed upon oxidation among samples.

Trophic levels (TLs) were determined according to equation 1 where 2 corresponds to the TL of the organism selected as baseline (corbiculidae = primary consumer), $\delta^{15} \mathrm{~N}_{\text {consumer }}$ and $\delta^{15} \mathrm{~N}_{\mathrm{BL}}$ are the $\delta^{15} \mathrm{~N}$ of the consumer and the baseline, respectively, and $3.4(\%)$ is the mean trophic enrichment ${ }^{35}$.

$T L_{\text {consumer }}=2+\left(\delta^{15} N_{\text {consumer }}-\delta^{15} N_{B L}\right) / 3.4$

The biomagnification of PFASs was assessed using two metrics: $\mathrm{BMF}_{\mathrm{TL}}$ (i.e. TL-normalized BMF) and TMF. BMF $\mathrm{TL}_{\mathrm{TL}}$ was calculated using equation 2 where $\mathrm{C}_{\text {predator }}$ and $\mathrm{C}_{\text {prey }}$ are the PFAS concentrations $\left(\mathrm{ng} \mathrm{g}^{-1}\right.$ ww whole body) in the predator and in its prey, and $\mathrm{TL}_{\text {predator }}$ and $T \mathrm{~L}_{\text {prey }}$ their trophic level, respectively 5.

$B M F_{T L}=10^{\left[\frac{\log _{10}\left(C_{\text {predator }} / C_{\text {prey }}\right)}{T L_{\text {predator }}-T L_{\text {prey }}}\right]}$

Predator-prey relations were determined using $\delta^{15} \mathrm{~N}$ and $\delta^{13} \mathrm{C}$, as well as the existing knowledge about fish trophic ecology ${ }^{36}$.

TMFs were obtained using the slope of the linear regression between the concentration (logtransformed, $\mathrm{ng} \mathrm{g}^{-1} \mathrm{ww}$ ) and TL (equation 3 and 4), using the function Imec (linear mixed-effects models 
with censored data) from the LMEC R package ${ }^{11}$. The TMF calculation was performed only for compounds with a detection frequency $>40 \%{ }^{37}$.

$$
\begin{aligned}
& \text { LogC }=\sim T L+1 \mid \text { intercept } \\
& T M F=10^{\text {slope }}
\end{aligned}
$$

\section{Results and discussion}

\subsection{PFAS concentrations and composition profiles}

Among the 30 analyzed PFASs, 4:2 FTSA, MeFOSA, EtFOSA, 8:2 diPAP, HFPO-DA and ADONA were never detected. The detection frequency and the mean concentrations of the other PFASs are provided in the ESI (Tables S9-S11), while LPFASs and molecular patterns are illustrated by Figure 1.

A single water sample was analyzed to indicate an order of magnitude of PFAS concentrations in this compartment. 13 PFASs were detected and LPFASs was $101.4 \mathrm{ng} \mathrm{L}^{-1}$. The predominant compound was PFOS followed by $\mathrm{C}_{4}-\mathrm{C}_{8}$ PFCAs and PFHxS, which individual concentrations ranged between 4.9 and 28.8 $\mathrm{ng} \mathrm{L}^{-1}$. Long-chain PFCAs $\left(\mathrm{C}_{11}-\mathrm{C}_{14}\right)$, PFDS, 8:2 FTSA, 10:2 FTSA and alkyl-FASAs were not detected. Among pre-PFAAs targeted, only 6:2 FTSA and FOSA were found at respective concentrations of 8.0 and $0.21 \mathrm{ng} \mathrm{L}^{-1}$.

In sediments $(n=3), 12$ PFASs were detected and $\sum$ PFASs was variable $\left(2.3 \pm 2.3 \mathrm{ng} \mathrm{g}^{-1}\right)$. Short-chain PFAAs (e.g., PFBA and PFBS) were not found, likely because of their low sediment-water partitioning coefficient $\left(K_{D}\right){ }^{25}$. PFDoDA, PFOS and PFTeDA dominated the molecular pattern with mean concentrations of $0.72,0.53$ and $0.47 \mathrm{ng} \mathrm{g}^{-1}$, respectively. Among pre-PFAAstargeted, 10:2 FTSA, 6:2 diPAP and EtFOSAA in sediments were either not detected or found at levels close to the LOD. Overall, ¿pre-PFAAstargeted represented less than $8 \%$ of $\sum$ PFASs in both abiotic compartments. Note that the 
reported PFAA concentrations and patterns are consistent with those previously observed at this site ${ }^{25}$ and exceed the average value determined at French nationwide scale for both water and sediments 19.

In biota samples, the detection frequency of $\mathrm{C}_{11}-\mathrm{C}_{14}$ PFCAs, PFOS and 10:2 FTSA was $100 \%$, while $\mathrm{C}_{8}-$ $\mathrm{C}_{10}$ PFCAs, PFDS, 8:2 FTSA, FOSA, MeFOSAA and EtFOSAA were detected in more than $80 \%$ of samples. Short-chain PFAAs were not found since they are quickly excreted and, consequently, poorly bioaccumulated ${ }^{38}$. The average PPFASs ranged between 59.5 and $147 \mathrm{ng} \mathrm{g}^{-1} \mathrm{ww}$ in fish with an interindividual variability lower than $30 \%$ within the same species (Figure 1A). These levels are, for instance, of the same order of magnitude than previously published values for whole fish (including juveniles and adults) from other sites in France (Rhône River and Gironde estuary) ${ }^{11,18}$ or in the United States (Ohio, Missouri and Upper Mississippi Rivers) ${ }^{39}$.

Total PFAS levels were significantly different between fish species: bullhead and common perch had higher $\sum$ PFAS levels than catfish, tench and gudgeon while roach was more contaminated than catfish and tench. Except for PFDS, significant differences between taxa were also found for the most frequently detected PFASs when considered individually. Such differences might be partly explained by the dietary behavior of these taxa. Overall, piscivorous fish generally present higher LPFASs than omnivorous and herbivorous species ${ }^{40}$. Bullhead and common perch may feed on fish juveniles ${ }^{36}$. The isotopic carbon signature is usually used to identify the feeding behavior since $\delta^{13} \mathrm{C}$ values are not impacted by trophic enrichment ${ }^{35}$. Bullhead and common perch exhibited the narrowest range of $\delta^{13} \mathrm{C}$ values (-26.2 - -25.5\%o and $-26.7--26.0 \%$, respectively) (Figure S4). Tench and catfish seemed to have a different and more varied diet, showing slightly more negative and higher amplitude of $\delta^{13} \mathrm{C}$ values $\left(-27.1--26.1 \%\right.$ and $-27.8--26.8 \%$, respectively). The widest range of $\delta^{13} \mathrm{C}$ values was observed for roach (-27.9- -26.1\%o), a known omnivorous species. The mean $\delta^{13} \mathrm{C}$ of fish ranged from -27.9 to $-25.5 \%$ and was framed by those of invertebrates that varied between $-30.2 \%$ 
(Notonectidae) and $-24.4 \%$ (Corbiculidae), suggesting that carbon sources exploited by fishes were appropriately taken into account.

Notonectidae were the most contaminated invertebrate taxon with EPFASs (84.6 $\mathrm{ng} \mathrm{g}^{-1} \mathrm{ww}$ ) comparable to that of gudgeons and pumpkinseed, whereas corbiculidae presented the lowest levels (4.0 $\left.\mathrm{ng} \mathrm{g}^{-1} \mathrm{ww}\right)$ similar to those observed in biofilm (2.9-3.2 $\left.\mathrm{ng} \mathrm{g}^{-1} \mathrm{ww}\right)$, macrophyte (4.8-5.1 $\left.\mathrm{ng} \mathrm{g}^{-1} \mathrm{ww}\right)$ and leaf litter (2.0-3.0 ng g-1 $\mathrm{ww})$. Notonectidae are mainly insectivorous and they are expected to feed essentially on insect larvae whereas corbiculidae are filter feeders; in addition, notonectidae are air breather insects, which may favor PFAS bioaccumulation ${ }^{8}$. These results are still to be confirmed with a larger sample set. The mean $\sum$ PFASs in gammarids was $47.0 \pm 2.5 \mathrm{ng} \mathrm{g}^{-1} \mathrm{ww}$, about 7 times lower than in the Rhône River ${ }^{18}$ and about 5 times higher than in the Gironde Estuary ${ }^{11}$.

The dominant compounds in biota were PFOS, PFDoDA and PFTeDA which, on average, contributed to $31 \%, 28 \%$ and $16 \%$ of $\sum$ PFASs, respectively (Figure $1 \mathrm{~b}$ ). Labadie and Chevreuil (2011) reported a larger predominance of PFOS (76\% in average) in tissues of European chub Squalius cephalus collected at the same site in $2010^{25}$. In this study, the highest PFOS relative abundance was found in pumpkinseed (47\%) common perch (43\%), barbel (43\%) and tench (42\%). PFDoDA was dominant in lymnaeidae (42\%), gammarids (37\%), catfish (33\%) and gudgeon (31\%) whereas PFTeDA dominated the PFAS composition in corbiculidae (49\%). The largest proportion of $\sum C_{4}-C_{8}$ PFCAs (3-7\%) were found in gammarids, corbiculidae, biofilm and macrophyte, in agreement with previous results ${ }^{10}$. Physiological characteristics, biotransformation capacities, life traits and feeding behavior might result in different exposure routes to PFAAs and their precursors, thereby possibly explaining these differences.

As for the abiotic compartment, $\sum$ pre-PFAAs targeted represented on average less than $5 \%$ of $\sum$ PFASs in biota. The highest relative abundances were found in corbiculidae (18\%), biofilm (13-17\%) and lymnaeidae (9-12\%). 10:2 FTSA was the dominant precursor in all biota samples (except notonectidae) with concentrations ranging from $0.16 \mathrm{ng} \mathrm{g}^{-1} \mathrm{ww}$ (macrophyte) to $3.2 \mathrm{ng} \mathrm{g}^{-1} \mathrm{ww}$ (barbel). To our knowledge, its presence in aquatic organisms has never been reported before. Other recurring 
precursors were FOSA, 6:2 FTSA and 8:2 FTSA (Tables S10 and S11). The presence of 6:2 diPAP was also reported in $59 \%$ of biota samples but this compound was systematically detected at low levels (<LOQ).

\subsection{Biomagnification of PFAAs: BMFTL and TMF}

The combined use of $\mathrm{C}$ and $\mathrm{N}$ stable isotopes allowed for the determination of the trophic web structure (Figure S4). Biofilm ( $T L=1.1)$ and macrophyte $(T L=1.2)$ were found at the lowest trophic positions, followed by corbiculidae $(T L=2.0)$, gammarids $(T L=2.0)$ and lymnaeidae $(T L=2.2)$. Fish $T L s$ ranged between 2.8 and 3.4 with barbel and catfish at the top of the food web.

$\mathrm{BMF}_{\mathrm{TL}}$ were calculated for a total of 9 well-established predator-prey pairs ${ }^{36}$; data ranges are shown in Table 1 while detailed values for each predator-prey pair are provided in Table S12. BMF systematically $>1$ were estimated for $\mathrm{C}_{11}-\mathrm{C}_{14}$ PFCAs, PFOS, PFDS and 10:2 FTSA. As regards PFAAs, these results are consistent with previous reports ${ }^{7,11,18}$ while these are the first $\mathrm{BMF}_{\mathrm{TL}}$ values reported for 10:2 FTSA. High variability of BMF $\mathrm{BM}_{\mathrm{TL}}$ was found for several compounds, including PFOS, PFTrDA or PFTeDA, depending on prey-predator pairs. For PFOS $\left(\mathrm{BMF}_{\mathrm{TL}}=2-169\right)$, the highest value was observed for the roach-lymnaeidae pair while the lowest one was calculated for the catfish-gammarid pair. This is partly due to the fact that such invertebrates with close TLs may exhibit contrasted contamination levels, as a result of different feeding behavior or differences in the ability to biotransform and eliminate chemicals ${ }^{41}$.

Considering the variability of $\mathrm{BMF}_{\mathrm{TL}}$ observed for several PFAAs, the use of TMF appeared more relevant, since it is a more integrative and holistic metrics that reflects the mean behavior of a chemical in a food web comprising complex trophic relations ${ }^{5}$. TMFs ranged from 0.2 to 5.5 (Table 1; slope and intercept values of the regression lines given in Table S13). As indicated by TMF $>1, C_{9}-C_{14}$ PFCAs, PFHpS, PFOS, PFDS, 8:2 FTSA, 10:2 FTSA, FOSA, MeFOSAA, EtFOSAA appeared to biomagnify in this trophic web, contrary to shorter chain-PFCAs, e.g. 6:2 FTSA or PFOA. The highest TMFs were 
determined for PFDS and 10:2 FTSA and a significant increase of TMF with chain length was observed for PFCAs $\left(C_{9}-C_{14}\right)$ (Spearman test: $p$-value $=0.004$, rho $\left.=0.90\right)$. For the latter compounds, such a trend has already been reported in lake and marsh ecosystems ${ }^{6-9}$, whereas decreasing TMF with increasing chain length was reported in an estuarine benthic food web ${ }^{11}$. These differences further suggest that the chemical structure and, hence, the chemical properties of PFASs are not the only determinant of biomagnification and that ecosystem characteristics, contamination pattern and exposure routes likely contribute to the TMF variability.

$\operatorname{TMF}_{\text {PFOS }}(1.5 \pm 0.1)$ was comparable to that reported for a subtropical marsh food web in Hong-Kong ${ }^{9}$, the estuarine trophic web from the Gironde in France ${ }^{11}$ or the marine bottlenose dolphin food web from Charleston Harbor (based on estimated whole body burden) ${ }^{7}$. The TMFs of long-chain PFCAs were also in the range of values previously reported for marine and freshwater ecosystems ${ }^{7-10}$.

Pre-PFAAs were seldom investigated in previous works, with the notable exception of FOSA. In agreement with our results, several studies reported $\mathrm{TMF}_{\mathrm{FOSA}}>1^{7,8,11,42}$ whereas $\mathrm{TMF}_{\mathrm{FOSA}}<1$ was reported for a lake Ontario foodweb ${ }^{6}$. MeFOSAA was not biomagnified in the Gironde estuary (TMF = 0.18) ${ }^{11}$, unlike in the present work; this suggests that the oxidation of MeFOSAA precursors may occur in the trophic web of the Orge river (see section 3.3). To our knowledge, the trophic magnification of FTSAs and diPAPs has never been studied before. In the Orge river, 6:2 FTSA was not biomagnified contrary to its homologues with longer perfluoroalkyl chains, probably because the elimination rates of PFASs increase with decreasing chain length ${ }^{38}$. In addition, the TMF of 6:2 diPAP appeared to be 
close to 1 but not significantly $>1$ and, thus, further data are needed to better estimate its biomagnification potential.

\subsection{Trophic transfer of pre-PFAAstargeted}

The biotransformation of (alkyl-)FASAs and (alkyl-)FASAAs can lead to the formation of PFOS while FTSAs and diPAPs can be converted into PFCA homologues with similar or lower number of perfluorinated carbon atoms ${ }^{43}$. The ratio between the concentrations of pre-PFAAstargeted and those of PFAAs was investigated at different TLs, as a proxy of precursor biotransformation in the food web ${ }^{17}$. Leaf litter was also included in the analysis, with an estimated TL of 0.8 (based on its $\delta^{15} \mathrm{~N}$ signature).

Log $\sum$ pre-PFOS targeted (i.e. FOSA and (alkyl-)FASAAs) to PFOS concentration ratios were plotted against TL and no significant trend was observed (Figure 2a). However, the mean ratio was significantly higher in invertebrates $(0.42 \pm 0.57)$ than in fish $(0.02 \pm 0.01)$; this suggests that the biotransformation of prePFOS might occur at the highest TLs, likely because fish have higher metabolic capacities than invertebrates. Previous studies reported on the metabolization of EtFOSA to FOSA and of FOSA to PFOS by the rainbow trout Onchorhynchus mykiss ${ }^{15,16}$. Babut et al. (2017) showed that FOSA/ MeFOSAA ratios varied between fish species and that the mean value was lower in invertebrates than in fish, thereby suggesting the increase of biotransformation rates of MeFOSAA at the highest TLs ${ }^{18}$. However, in the present study, similar TMFs were observed for MeFOSAA, EtFOSAA and PFOS, indicating that the biotransformation of MeFOSAA and EtFOSAA precursors occurred in this trophic web (e.g. $\mathrm{N}$ ethylperfluorooctane sulfonamidoethanol, EtFOSE). ${ }^{18,44}$ The latter hypothesis might also explain why the $\sum$ pre-PFOS targeted to PFOS concentration ratio was significantly higher in invertebrates than in biofilm and leaf litter, suggesting that the biotransformation of unidentified (alkyl-)FASAA precursors present in water, sediments, biofilm or leaf litter also occurs in invertebrates. 
Unlike in fish, $\sum$ pre-PFOS targeted/PFOS concentration ratios exhibited large variations between invertebrate taxa (variation coefficient of $134 \%)$. Corbiculidae (1.69) and lymnaeidae (0.47) displayed higher ratios than gammarids $(0.08)$ or notonectidae $(0.03)$, possibly because of higher pre-PFOS metabolization capacities in the latter taxon (Figure S6). In addition to taxon-specific metabolic capacities or exposure routes, PFAS toxicokinetics might also differ between taxa ${ }^{45}$.

Log $\sum$ pre-PFCAstargeted (i.e. all pre-PFAAs targeted except FOSA and (alkyl-)FASAAs) to PPFCAs concentration ratios were negatively correlated with TLs (Figure 2b), clearly indicating an increase of the biotransformation rates of pre-PFCAs into PFCAs along the trophic web. To date, the biotransformation of FTSA and diPAPs has been little studied in aquatic organisms. Yeung and Mabury (2013) demonstrated that the biotransformation of 6:2 and 8:2 FTSA by juvenile rainbow trout (Oncorhynchus mykiss) could induce the formation of 5:3 and 7:3 FTCA, respectively, and subsequently $\mathrm{C}_{5}-\mathrm{C}_{8}$ PFCAs. In the same line, the metabolization of 10:2 FTSA (i.e. the most abundant pre-PFAAs targeted $_{\text {in }}$ the biota from the Orge River), could significantly contribute to the formation of longer-chain PFCAs (e.g. $C_{9}-$ $C_{10}$ ) along the trophic web. Further investigation of 10:2 FTSA biotransformation kinetics would therefore be helpful to estimate its contribution to PFNA and PFDA bioaccumulation. The fate of 8:2 diPAP was recently assessed for the first time in a marine fish species (Sparus aurata) ${ }^{16}$. The biotransformation of 8:2 diPAP yielded saturated and unsaturated fluorotelomer carboxylic acids (FTCAs and FTUCAS, respectively), as well as PFOA. These findings suggest that 6:2 diPAP could be metabolized similarly, yielding shorter-chain fluorotelomer carboxylic acids and PFCAs. As observed for (alkyl-)FASAAs, increasing concentrations of these pre-PFAAs along the Orge River trophic web suggest that the metabolization of their unidentified precursors occurs in this food web. 


\subsection{Trophic transfer of pre-PFAAsunknown}

To get further insight into the bioaccumulation of organic fluoride in fish exposed to AFFF formulations, Yeung and Mabury ${ }^{47}$ implemented a mass balance analysis based on the determination of both total fluorine (TF) and extractable organic fluorine (EOF) in fish tissues. They demonstrated that known PFASs explained only $0.9-7 \%$ of EOF in unexposed fish and $<7 \%-60 \%$ in exposed fish. They concluded that both known PFASs and unknown organofluorines could be bioconcentrated in fish tissues.

To investigate whether unknown PFASs could play a role in the trophic magnification of PFAAs in the Orge River, the TOP assay was applied to selected samples: water $(n=1)$, sediment $(n=1)$ and biota ( $n=15)$. Upon oxidation, positive $\triangle$ PFCAs were systematically observed, i.e. $+15-424 \%$, depending on the sample (Table S14). The largest relative increase was found at the base of the trophic web, e.g. in biofilm (424\%), sediment (319\%), leaf litter (298\%), and macrophytes (196\%). On the contrary, the lowest $\triangle \mathrm{PFCAs}$ was found in fish, especially in catfish (+ 15-22\%). Note that, the limited number of considered samples does not allow for inter-individual nor spatial variability. While a significant increase of $\mathrm{C}_{4}-\mathrm{C}_{12}$ PFCA concentrations was observed in all samples upon oxidation, this was not the case for PFTrDA and PFTeDA. Thus, pre-PFAAs unknown bearing perfluoroalkyl chains with more than 12 carbons were either absent or present at extremely low levels in these samples, suggesting that the biomagnification of PFTrDA and PFTeDA was not affected by the biotransformation of precursors. These results are consistent with previous reports on the lack of very long-chain PFCA precursors in urban runoff and waste water effluent, indicating that they were little emitted into the aquatic environment ${ }^{28,29,31}$.

The profiles of PFCAs formed upon oxidation ( $\triangle \mathrm{PFCA}$ ) are presented in Figure 3. While these patterns cannot be directly associated to precursors chain length profiles since oxidation of some precursors leads to the formation of a series of variable chain-length PFCAs, such information are used to provide general insights on the range of chain length of unknown PFAA-precursors homologues present in the different matrixes and a large approximation of their relative abundance. Different patterns of PFCAs 
formed upon oxidation were observed between samples as highlighted by hierarchical clustering analysis based on Euclidian distance. In water, PFPeA presented the largest increase $\left(+24.4 \mathrm{ng} \mathrm{L}^{-1}\right.$, i.e. $+202 \%$ ) followed by PFHxA ( $+8.3 \mathrm{ng} \mathrm{L}^{-1}$, i.e. $+60 \%$ ) and PFHpA (+ $3 \mathrm{ng} \mathrm{L}^{-1}$, i.e. $+62 \%$ ) explaining $88 \%$ of $\triangle$ PFCAs. Although these compounds can result from the oxidation of precursors with higher number of perfluorinated carbon atoms (Table S8), the predominance of $\mathrm{C}_{4}-\mathrm{C}_{6}$ PFAA precursors in water would not be surprising for two reasons: i) the PFAS solubility decreases with increasing chain length and ii) regulatory bodies encourage the use of PFASs with less than 8 perfluorinated carbons. Among prePFAAstargeted, only 6:2 FTSA was detected in water and its concentration could explain $44 \%, 5 \%, 15 \%$ and $5 \%$ of the increase upon oxidation of PFBA, PFPeA, PFHXA and PFHpA levels, respectively. This strongly suggests the presence of unidentified short-chain pre-PFAAs in the water column, although chemicals behaving similarly to FTSAs or diPAPs upon oxidation could also yield such short-chain PFCAs. Some PFAA-precursors, including 6:2 FTSA, may also generate $C_{2}-C_{3}$ PFCAs upon TOP assay ${ }^{47}$. Ultrashort-chain PFASs, as named, were not addressed in the present study. However, a recent review pointed out that such PFASs pass through conventional wastewater treatment processes and were found in aqueous environment including rivers ${ }^{48}$.

In sediment and biota samples, the formation of $\mathrm{C}_{8}-\mathrm{C}_{12}$ PFCAs upon oxidation was more predominant than in water, explaining $40-70 \%$ of $\triangle \mathrm{PFCAs}$ (Figure 3). These results are consistent with previous reports indicating that both the $K_{D}$ and the bioaccumulation factor (BAF) of PFASs increase with increasing chain length ${ }^{25,41}$. It should be noted that no significant increase of PFDoDA concentrations was observed in lymnaeidae and catfish upon oxidation (blue cluster on Figure 3). Conversely, the largest $\triangle$ PFDoDA was observed in bullhead and its main prey, gammarids (black cluster on Figure 3). The reason for this observation remains unclear, considering that no such trend was observed in the gammarid main food sources (i.e. leaf litter and biofilm, grouped in red cluster on Figure 3).

¿pre-PFAAstargeted accounted for a higher contribution to $\triangle$ PFCAs in fish and invertebrates than at the base of the trophic web. For instance, based on the conversion factors obtained in ultra-pure water 
(Table S15), the oxidation of 10:2 FTSA would explain on average $38 \%$ of $\triangle$ PFDA in fish and invertebrates against less than $11 \%$ in sediments and biofilm. Altogether, 8:2 FTSA, 10:2 FTSA and sulfonamides would contribute to $23-63 \%$ of $\triangle \mathrm{PFOA}$ in fish and invertebrates against $3-11 \%$ in biofilm. The relative proportion of $\sum$ PFCAs, $\Sigma$ PFSAs, $\sum$ pre-PFAAs targeted $_{\text {and }} \sum$ pre-PFAAs unknown $_{\text {in }}$ in the trophic web of the Orge River is shown on Figure 4. In water and sediment, Epre-PFAAsunknown accounted respectively for $33 \%$ and $78 \%$ of $\sum$ PFASs. The contribution of pre-PFAAsunknown to $\sum$ PFASs in biofilm, leaf litter and macrophytes was in the same range that in sediment (64-80\%). Pre-PFAAs unknown accounted for $30-42 \%$ of $\sum$ PFASs in gammarids and lymnaeidae. In fish, the proportion of extractable $\sum$ prePFAAsunknown was similar between taxa (18-23\%) and was significantly lower than in invertebrates or abiotic samples. Thus, a significant sharp decrease of the $\sum$ pre-PFAAs unknown $_{2} / \sum$ PFAAs molar ratio was observed according to TL (Figure S7). Considering the large relative abundance of extractable prePFAAs unknown at the base of the trophic web, it is therefore likely that the biotransformation of these chemicals contributes to the observed increase of the levels of some PFCAs and PFSAs at the higher TLs (i.e. $C_{9}-C_{12}$ PFCAs and $C_{7}-C_{10}$ PFSAs, based on the profiles of PFAAs formed upon oxidation, see Figure S7 and discussion above). The actual contribution of pre-PFAAs unknown to the biomagnification of these PFAAs cannot currently be estimated because i) the structure of prePFAAsunknown occurring in the Orge River remains by definition undetermined at this stage, ii) the individual conversion rates and oxidation product patterns of these compounds using the TOP assay are unknown and iii) toxicokinetics may differ among these compounds. Additionally, the TOP assay process does not mime biotransformation meaning that results from such approach cannot be directly used in the state to quantify the precursors contribution to the biomagnification of individual PFAAs. Indeed, Indeed, PFCAs formed upon oxidation do not systematically correspond to biotransformation products. For instance, PFOA is the main and single product of FOSA and MeFOSAA oxidation upon TOP assay (refer to Table S15) whereas PFOS has been identified as their major products through biotransformation ${ }^{15,49}$. However, our results strongly point to the biotransformation of unattributed precursors along this trophic web that warrants further investigation. 
Additionally, these results might also indicate that extractable sediment-bound unattributed precursors are either mainly metabolized by invertebrates or are poorly bioavailable. It should also be noted that no correlation was observed between $\sum$ pre-PFAAs unknown $/ \sum$ PFAAs and $\delta^{13} C$, indicating the absence of an obvious relationship between carbon sources and exposure to pre-PFAAs.

\section{Conclusion}

The bioaccumulation and biomagnification of PFAAs in aquatic biota have raised a growing concern over the last 15 years. Numerous studies have addressed this issue but very few investigated the role of pre-PFAAs in such processes. Here, an original approach was implemented based on i) the quantitative analysis of selected pre-PFAAS and ii) on the estimation of unknown extractable pre-PFAAs via the TOP assay. Such a strategy was applied to the food web of the Orge River that may be considered as a typical urban river, i.e. with point and diffuse inputs of PFASs mainly linked to domestic sources and atmospheric deposition.

While selected precursors overall accounted for a relatively minor proportion of $\Sigma$ PFASs, the TOP assay revealed the occurrence of substantial proportions of extractable unknown pre-PFAAs in all compartments of the Orge River trophic web. Sediments appear to be a sink for a complex mixture of unidentified pre-PFAAs and a source of long-chain fluoroalkyl chemicals that, upon biotransformation, could significantly contribute to the biomagnification of PFAAs (i.e. $C_{T}-C_{10}$ PFSAs and $C_{9}-C_{12}$ PFCAs in the present study). Thus, these results highlight the need of future research to get further insight into the exposure of aquatic biota to PFASs and into the trophodynamics of these chemicals. There is a clear need to identify the structure of the unattributed PFAA precursors occurring in the environment using a complementary approach (e.g. TOP and extractable organic fluorine assays vs suspect or nontarget screening based on high-resolution mass spectrometry). Further investigation of the toxicokinetics of newly identified pre-PFAAs is essential. The determination of biotransformation rates in biofilm, invertebrates and selected fish species would allow to accurately quantifying their 
contribution to PFAA biomagnification, thereby contributing to better explain the spatial variability of

TMFs. Additionally, modelling and experimental studies performed under controlled conditions would help getting further insight into the actual contribution of pre-PFAAs to PFAA biomagnification.

\section{Conflicts of interest}

There are no conflicts of interest to declare

\section{Acknowledgements}

This study has been carried out under the framework of the PIREN-Seine project and with financial support from the French National Research Agency (ANR). This study was conducted in the frame of the "Investments for the future" Program, within the Cluster of Excellence COTE (ANR-10-LABX-45). The authors also acknowledge funding from the Aquitaine Regional Council and the European Regional Development Fund (FEDER).

\section{References}

1 L. Ahrens, Polyfluoroalkyl compounds in the aquatic environment: A review of their cccurrence and fate. J. Environ. Monit., 2011, 13, 20-31.

2 R. C. Buck, J. Franklin, U. Berger, J. M. Conder, I. T. Cousins, P. de Voogt, A. A. Jensen, K. Kannan, S. A. Mabury and S. P. J. van Leeuwen, Perfluoroalkyl and polyfluoroalkyl substances in the environment: terminology, classification, and origins. Integr. Environ. Assess. Manag., 2011, 7, $513-541$.

3 J. P. Giesy and K. Kannan, Global distribution of perfluorooctane sulfonate in wildlife. Environ. Sci. Technol., 2001, 35, 1339-1342.

4 M. Houde, A. O. De Silva, D. C. G. Muir and R. J. Letcher, Monitoring of perfluorinated compounds in aquatic biota: An updated review Environ. Sci. Technol., 2011, 45, 7962-7973.

5 J. M. Conder, F. A. P. C. Gobas, K. Borga, D. C. G. Muir and D. E. Powell, Use of trophic magnification factors and related measures to characterize bioaccumulation potential of 
chemicals. Integr. Environ. Assess. Manag., 2011, 8, 85-97.

J. W. Martin, D. M. Whittle, D. C. G. Muir and S. A. Mabury, Perfluoroalkyl contaminants in a food web from Lake Ontario. Environ. Sci. Technol., 2004, 38, 5379-5385.

M. Houde, T. a D. Bujas, J. Small, R. S. Wells, P. a Fair, G. D. Bossart, K. R. Solomon and D. C. G. Muir, Biomagnification of perfluoroalkyl compounds in the bottlenose Dolphin (Tursiops Truncatus). Environ. Sci. Technol., 2006, 40, 4138-44.

B. C. Kelly, M. G. Ikonomou, J. D. Blair, B. Surridge, D. Hoover, R. Grace and F. A. P. C. Gobas, Perfluoroalkyl contaminants in an Arctic marine food web: Trophic magnification and wildlife exposure. Environ. Sci. Technol., 2009, 43, 4037-4043.

E. I. H. Loi, L. W. Y. Yeung, S. Taniyasu, P. K. S. Lam, K. Kannan and N. Yamashita, Trophic magnification of poly- and perfluorinated compounds in a subtropical food web. Environ. Sci. Technol., 2011, 45, 5506-5513.

J. Xu, C. Guo, Y. Zhang and W. Meng, Bioaccumulation and trophic transfer of perfluorinated compounds in a eutrophic freshwater food web. Environ. Pollut., 2014, 184, 254-261.

G. Munoz, M. Babut, H. Drouineau, M. Lauzent, K. Le Menach, J. Selleslagh, C. Simonnet-laprade and P. Labadie, Evidence for the trophic transfer of perfluoroalkylated substances in a temperate macrotidal estuary. Environ. Sci. Technol., 2017, 51, 8450-8459.

12 J. Franklin, How reliable are field-derived biomagnification factors and trophic magnification factors as indicators of bioaccumulation potential? Conclusions from a case study on per- and polyfluoroalkyl substances. Integr. Environ. Assess. Manag., 2016, 12, 6-20.

J. P. Benskin, A. O. De Silva, L. J. Martin, G. Arsenault, R. McCrindle, N. Riddell, S. A. Mabury and J. W. Martin, Disposition of perfluorinated acid isomers in Sprague-Dawley Rats; Part 1: Single Dose. Environ. Toxicol. Chem., 2009, 28, 542-554.

G. T. Tomy, S. A. Tittlemier, V. P. Palace, W. R. Budakowski, E. Braekevelt, L. Brinkworth and K. Friesen, Biotransformation of $\mathrm{N}$-ethyl perfluorooctanesulfonamide by Rainbow Trout (Onchorhynchus mykiss) liver microsomes. Environ. Sci. Technol., 2004, 38, 758-762.

S. H. Brandsma, M. Smithwick, K. Solomon, J. Small, J. De Boer and D. C. G. Muir, Dietary exposure of Rainbow Trout to $8: 2$ and 10:2 fluorotelomer alcohols and perfluorooctanesulfonamide: uptake, transformation and elimination. Chemosphere, 2011, 82, 253-258.

I. Zabaleta, E. Bizkarguenaga, U. Izagirre, N. Negreira, A. Covaci, J. P. Benskin, A. Prieto and O. Zuloaga, Biotransformation of 8:2 polyfluoroalkyl phosphate diester in Gilthead Bream (Sparus Aurata). Sci. Total Environ., 2017, 609, 1085-1092.

W. A. Gebbink, A. Bignert and U. Berger, Perfluoroalkyl acids (PFAAs) and selected pecursors in the Baltic Sea Environment: Do precursors play a role in food web accumulation of PFAAs? Environ. Sci. Technol., 2016, 50, 6354-6362.

M. Babut, P. Labadie, C. Simonnet-Laprade, G. Munoz, M. C. Roger, B. J. D. Ferrari, H. Budzinski and E. Sivade, Per- and poly- fluoroalkyl compounds in freshwater fish from the Rhône River: Influence of fish size, diet, prey contamination and biotransformation. Sci. Total Environ., 2017, 605-606, 38-47.

G. Munoz, J.-L. Giraudel, F. Botta, F. Lestremau, M.-H. Dévier, H. Budzinski and P. Labadie, spatial distribution and partitioning behavior of selected poly- and perfluoroalkyl substances in freshwater ecosystems: A French nationwide survey. Sci. Total Environ., 2015, 517, 48-56. 
J. A. Field and J. Seow, Properties, occurrence, and fate of fluorotelomer sulfonates (Critical Reviews). Environ. Sci. Technol., 2017, 47, 643-691.

21 S. A. Mabury, Production of perfluorinated carboxylic acids (PFCAs) from the biotransformation of polyfluoroalkyl phosphate surfactants (PAPs): Exploring routes of Human contamination. Environ. Sci. Technol., 2007, 41, 4799-4805.

22 N. Wang, J. Liu, R. C. Buck, S. H. Korzeniowski, B. W. Wolstenholme, P. W. Folsom and L. M. Sulecki, 6:2 Fluorotelomer sulfonate aerobic biotransformation in activated sludge of waste water treatment plants. Chemosphere, 2011, 82, 853-858.

23 M. Lewis, M. Hee, E. J. Liu, N. Wang and K. Chu, Biotransformation of 6:2 polyfluoroalkyl phosphates (6:2 PAPs): Effects of degradative bacteria and co-substrates. J. Hazard. Mater., 2016, 320, 479-486.

24 J. C. D'Eon, P. W. Crozier, V. I. Furdui, E. J. Reiner, E. L. Libelo and S. A. Mabury, Perfluorinated phosphonic acids in Canadian surface waters and wastewater treatment plant effluent: discovery of a new class of perfluorinated acids. Environ. Toxicol. Chem., 2009, 28, 2101-2107.

25 P. Labadie and M. Chevreuil, Partitioning behaviour of perfluorinated alkyl contaminants between water, sediment and fish in the Orge River (nearby Paris, France). Environ. Pollut., 2011, 159, 391-397.

26 Z. Wang, I. T. Cousins, M. Scheringer and K. Hungerbühler, Fluorinated alternatives to Longchain perfluoroalkyl carboxylic acids (PFCAs), perfluoroalkane sulfonic acids (PFSAs) and their potential precursors. Environ. Int., 2013, 60, 242-248.

27 E. F. Houtz, C. P. Higgins, J. A. Field and D. L. Sedlak, Persistence of perfluoroalkyl acid precursors in AFFF-impacted groundwater and soil. Environ. Sci. Technol., 2013, 47, 8187-8195.

28 F. Ye, M. Tokumura, M. S. Islam, Y. Zushi, J. Oh and S. Masunaga, Spatial distribution and importance of potential perfluoroalkyl acid precursors in urban rivers and sewage treatment plant effluent - Case study of Tama River, Japan. Water Res., 2014, 67, 77-85.

29 E. F. Houtz, R. Sutton, J. S. Park and M. Sedlak, Poly- and perfluoroalkyl substances in wastewater: significance of unknown precursors, manufacturing shifts, and likely AFFF impacts. Water Res., 2016, 95, 142-149.

30 X. Dauchy, V. Boiteux, C. Bach, A. Colin, J. Hemard, C. Rosin and J. Munoz, Mass flows and fate of per- and polyfluoroalkyl substances (PFASs) in the wastewater treatment plant of a fluorochemical manufacturing facility. Sci. Total Environ., 2017, 576, 549-558.

31 E. F. Houtz and D. L. Sedlak, Oxidative conversion as a means of detecting precursors to perfluoroalkyl acids in urban runoff. Environ. Sci. Technol., 2012, 46, 9342-9349.

32 C. Froger, C. Quantin, J. Gasperi, E. Caupos, G. Monvoisin, O. Evrard and S. Ayrault, Impact of urban pressure on the spatial and temporal dynamics of PAH fluxes in an urban tributary of the Seine River (France). Chemosphere, 2019, 219, 1002-1013.

33 N. Bodin, H. Budzinski, K. Le Ménach and N. Tapie, ASE Extraction Method for Simultaneous Carbon and nitrogen stable isotope analysis in soft tissues of aquatic organisms. Anal. Chim. Acta, 2009, 643, 54-60.

34 J. L. Reiner, S. G. O'Connell, C. M. Butt, S. a. Mabury, J. M. Small, A. O. De Silva, D. C. G. Muir, A. D. Delinsky, M. J. Strynar, A. B. Lindstrom, W. K. Reagen, M. Malinsky, S. Schäfer, C. J. a F. Kwadijk, M. M. Schantz and J. M. Keller, Determination of perfluorinated alkyl acid concentrations in biological Standard Reference Materials. Anal. Bioanal. Chem., 2012, 404, 
2683-2692.

D. M. Post, Using stable isotopes to estimate trophic position: models, methods, and assumptions. Ecology, 2002, 83, 703-718.

P. Keith, H. Persat, E. Feunteun and J. Allardi, Les Poissons d'eau douce de France. Muséum national d'Histoire naturelle, Paris ; Biotope, Mèze, 552 p. (Inventaires \& biodiversité ; 1)., 2011.

D. R. Helsel, Statistics for censored environmental data using Minitab and R, John Wiley., 2011.

C. Lau, K. Anitole, C. Hodes, D. Lai, A. Pfahles-Hutchens and J. Seed, Perfluoroalkyl acids: a review of monitoring and toxicological findings. Toxicol. Sci., 2007, 99, 366-394.

X. Ye, M. J. Strynar, S. F. Nakayama, J. Varns, L. Helfant, J. Lazorchak and A. B. Lindstrom, Perfluorinated compounds in whole fish homogenates from the Ohio, Missouri, and Upper Mississippi Rivers, USA. Environ. Int., 2008, 156, 1227-1232.

L. Ahrens and M. Bundschuh, Fate and effects of poly- and perfluoroalkyl substances in the aquatic environment: A review. Environ. Toxicol. Chem., 2014, 33, 1921-1929.

41 J. M. Conder, R. A. Hoke, W. De Wolf, M. H. Russell and R. C. Buck, Are PFCAs bioaccumulative? A critical review and comparison with regulatory criteria and persistent lipophilic compounds. Environ. Sci. Technol., 2008, 42, 995-1003.

42 G. T. Tomy, K. Pleskach, S. Ferguson, G. Stern, G. Maclnnis, C. H. Marvin and L. Loseto, Trophodynamics of some PFCs and BFRs in a Western Canadian Arctic marine food web. Environ. Sci. Technol., 2009, 43, 4076-4081.

43 J. Liu and S. Mejia Avendaño, Microbial degradation of polyfluoroalkyl chemicals in the environment: A review. Environ. Int., 2013, 61, 98-114.

44 S. Zhao, X. Ma, S. Fang and L. Zhu, Behaviors of $N$-ethyl perfluorooctane sulfonamide ethanol (N-EtFOSE) in a soil-earthworm system: transformation and bioaccumulation. Sci. Total Environ., 2016, 554-555, 186-191.

45 D. Bertin, P. Labadie, B. J. D. Ferrari, A. Sapin, J. Garric, O. Geffard, H. Budzinski and M. Babut, Potential exposure routes and accumulation kinetics for poly- and perfluorinated alkyl compounds for a freshwater amphipod: Gammarus Spp. (Crustacea). Chemosphere, 2016, 155, 380-387.

46 L. W. Y. Yeung and S. A. Mabury, Bioconcentration of aqueous Film-Forming Foam (AFFF) in juvenile Rainbow Trout (Oncorhynchus mykiss). Environ. Sci. Technol., 2013, 47, 12505-12513.

47 J. Janda, K. Nödler, M. Scheurer, O. Happel, G. Nürenberg, C. Zwiener and F. T. Lange, Closing the gap - inclusion of ultrashort-chain perfluoroalkyl carboxylic acids in the total oxidizable precursor (TOP) assay protocol. Environ. Sci. Process. Impacts, 2019.

48 M. Ateia, A. Maroli, N. Tharayil and T. Karanfil, The overlooked short- and ultrashort-chain polyand perfluorinated substances: A review. Chemosphere, 2019, 220, 866-882.

49 J. Liu, G. Zhong, W. Li and S. M. Avendaño, Isomer-specific biotransformation of perfluoroalkyl sulfonamide compounds in aerobic soil. Sci. Total Environ., 2019, 651, 766-774. 


\section{Graphical abstract}

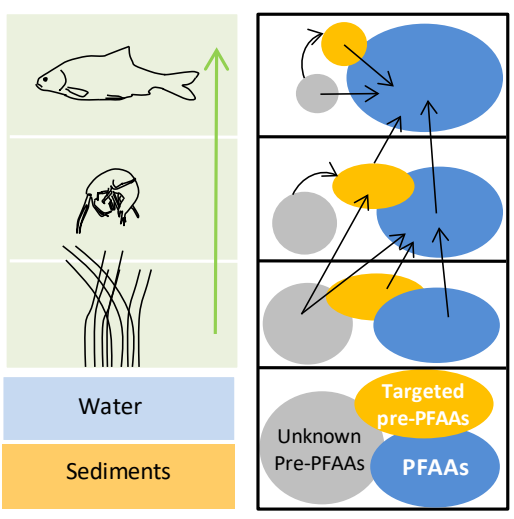

In the Orge River, the contribution of perfluoroalkyl acid precursors decreases between the base and the top of the trophic web. 

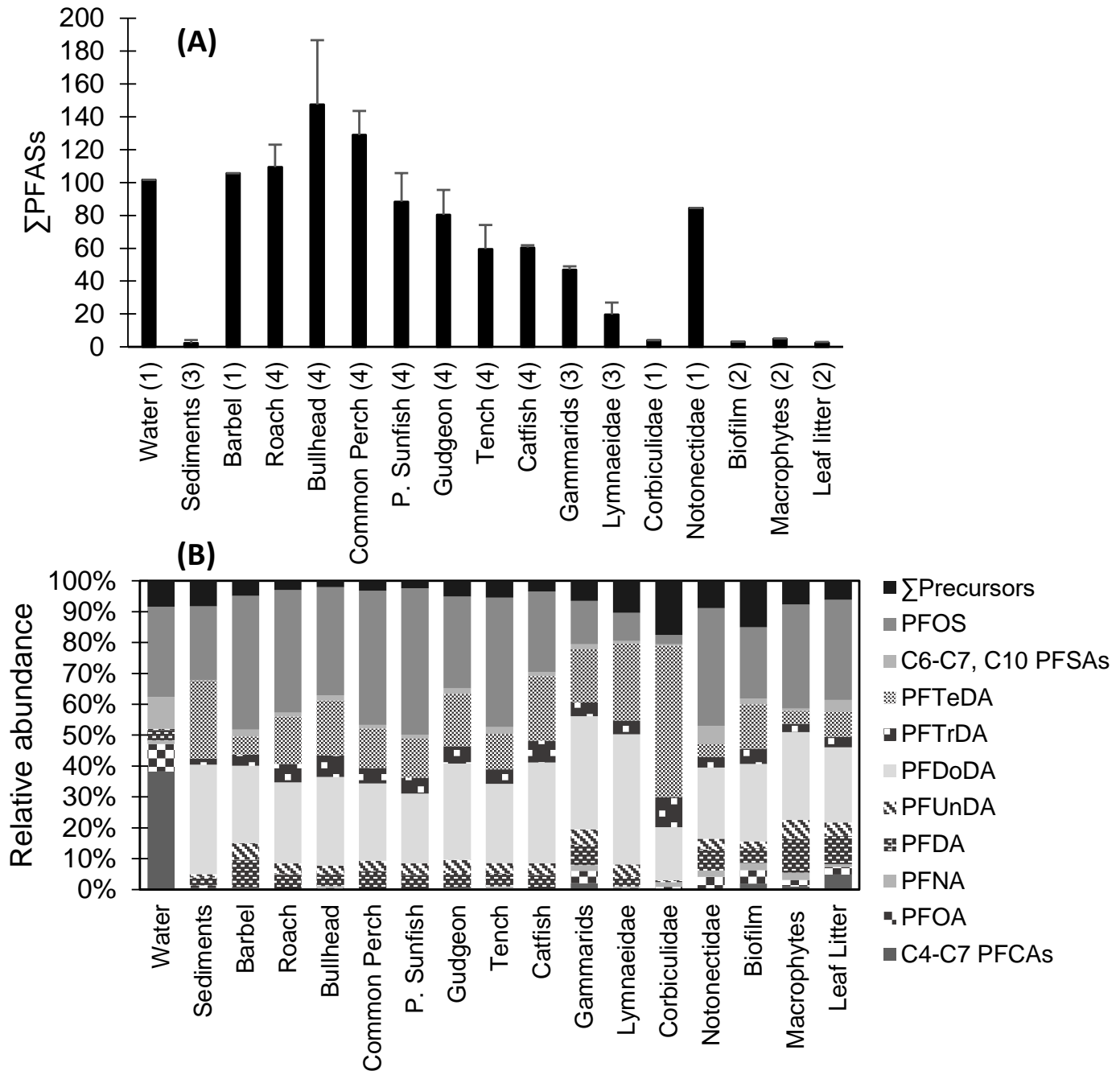

Figure 1: Mean total PFAS concentrations and molecular pattern in water, sediment and biota samples (the number of replicates is indicated between brackets). Concentrations are expressed in $\mathrm{ng} \mathrm{L}^{\mathrm{L}^{-1}}$ for water, $n g \mathrm{~g}^{-1} \mathrm{dw}$ for sediments and $\mathrm{ng} \mathrm{g}^{-1} \mathrm{ww}$ for biota samples. 
Table 1: BMFtL and TMF determined in the Orge River trophic web; values between brackets indicate the $95 \%$ confidence interval while bold characters denotes TMF values significantly higher than 1. L-PFOS: linear isomer of PFOS; Br-PFOS: sum of PFOS branched isomers.

\begin{tabular}{|c|c|c|c|c|}
\hline & $\begin{array}{c}\text { Detection } \\
\text { frequency (\%) }\end{array}$ & $\begin{array}{l}\text { Concentration } \\
\left.\text { range (ng g }{ }^{-1} \mathrm{ww}\right)\end{array}$ & $\begin{array}{c}\mathrm{BMF}_{\mathrm{TL}} \\
(\min -\max )\end{array}$ & TMF \\
\hline PFHXA & 39 & $<L D-0.57$ & not calculated & $0.2(0.2 ; 0.3)$ \\
\hline PFOA & 93 & $<\mathrm{LD}-3.19$ & $0.04-1.4$ & $0.6(0.5 ; 0.6)$ \\
\hline PFNA & 98 & $<L D-1.62$ & $0.3-2.3$ & $1.6(1.5 ; 1.7)$ \\
\hline PFDA & 90 & $<$ LD-9.56 & $0.9-25.2$ & $2.6(2.2 ; 3.0)$ \\
\hline PFUnDA & 100 & $0.02-5.98$ & $1.0-11.6$ & $2.2(2.1 ; 2.3)$ \\
\hline PFDoDA & 100 & $0.70-58.6$ & $1.1-6.9$ & $2.4(2.3 ; 2.5)$ \\
\hline PFTrDA & 100 & $0.13-14.1$ & $1.7-24.1$ & $2.9(2.8 ; 3.0)$ \\
\hline PFTeDA & 100 & $0.19-29.5$ & $1.4-15.8$ & $2.9(2.7 ; 3.0)$ \\
\hline PFHxS & 78 & $<\mathrm{LD}-4.47$ & 0.8 & not calculated \\
\hline PFHpS & 73 & $<\mathrm{LD}-0.50$ & 0.8 & $1.6(1.4 ; 1.8)$ \\
\hline$\sum$ PFOS & 100 & $0.12-84.0$ & $2.0-169$ & $1.5(1.4 ; 1.6)$ \\
\hline L-PFOS & 100 & $0.12-70.54$ & 2.1-173 & $1.6(1.5 ; 1.7)$ \\
\hline $\mathrm{Br}$-PFOS & 98 & $<\mathrm{LD}-13.50$ & $0.9-134$ & $1.8(1.7-2.0)$ \\
\hline PFDS & 100 & $0.02-2.10$ & $4.0-25.7$ & $5.5(5.3 ; 5.7)$ \\
\hline $6: 2$ FTSA & 76 & $<\mathrm{LD}-5.24$ & $0.2-2.5$ & $0.6(0.5 ; 0.6)$ \\
\hline 8:2 FTSA & 98 & $<$ LD-1.09 & $0.3-17.2$ & $1.3(1.2 ; 1.4)$ \\
\hline 10:2 FTSA & 100 & $0.16-3.23$ & $1.1-4.8$ & $3.0(3.0 ; 3.0)$ \\
\hline FOSA & 98 & $<L D-0.97$ & $0.6-1.6$ & $2.5(2.3 ; 2.6)$ \\
\hline FOSAA & 44 & $<\mathrm{LD}-0.12$ & not calculated & $0.6(0.5 ; 0.8)$ \\
\hline MeFOSAA & 80 & $<\mathrm{LD}-0.11$ & $0.8-2.5$ & $1.5(1.3 ; 1.6)$ \\
\hline EtFOSAA & 83 & $<\mathrm{LD}-0.16$ & $0.4-2.2$ & $1.5(1.3 ; 1.6)$ \\
\hline 6:2 diPAP & 59 & $<\mathrm{LD}-0.11$ & 1.7 & $1.2(0.9 ; 1.4)$ \\
\hline
\end{tabular}
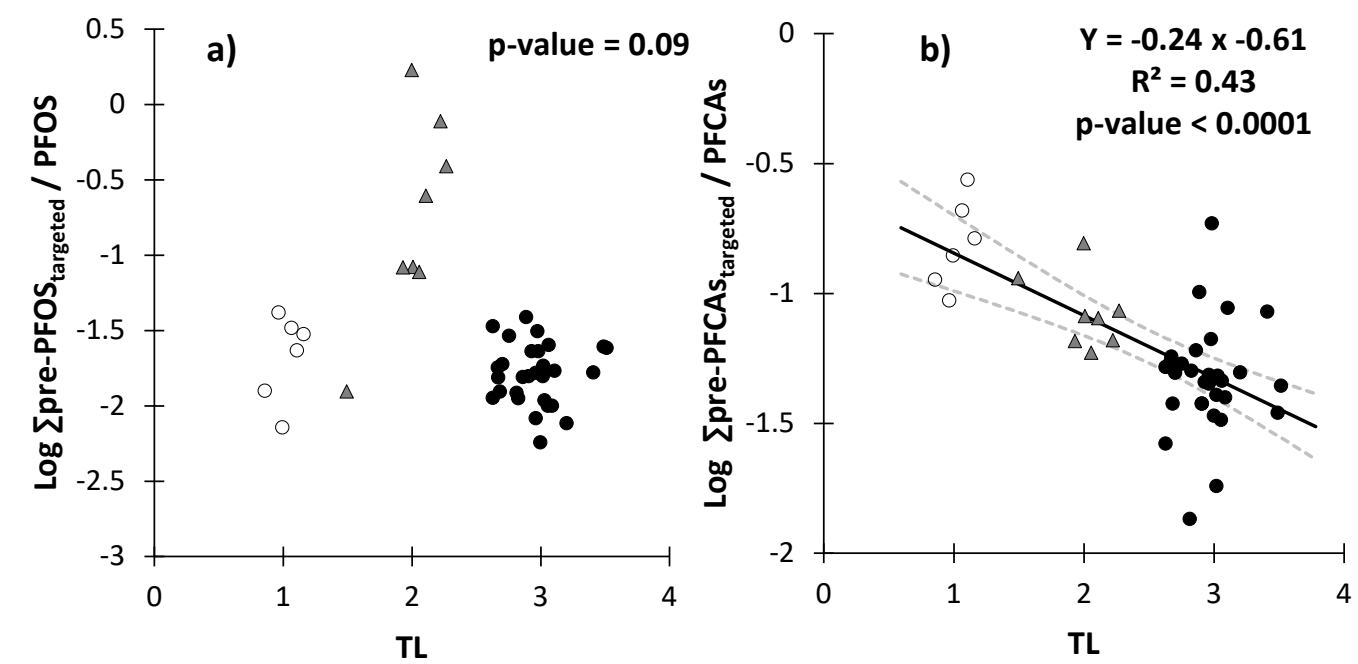

Figure 2: Log Epre-PFOS targeted/ PFOS molar concentration ratios (a) and Log 2pre-PFCAstargeted/PFCAs molar concentration ratios (b) according to the trophic level. White circles correspond to the base of the trophic web (e.g. biofilm, leaf litter and macrophytes), grey triangle and black circles refer to invertebrates and fish, respectively. 


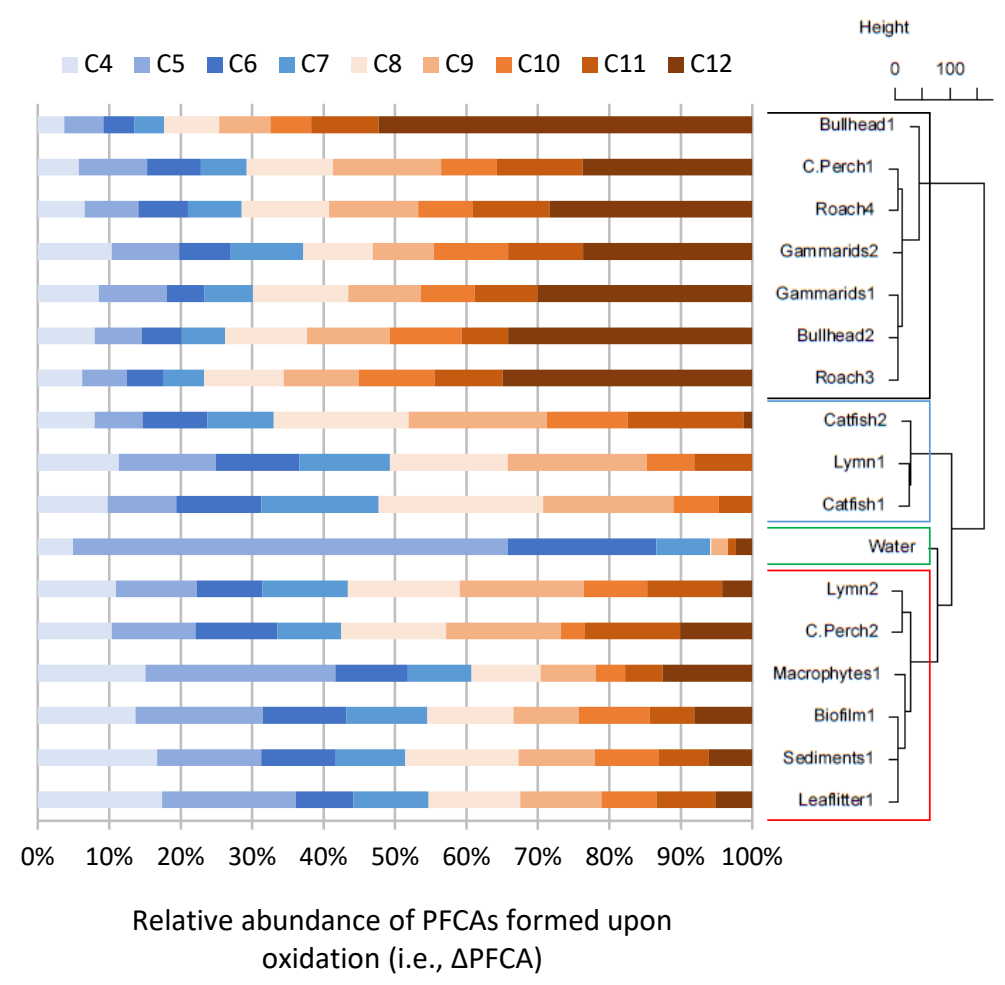

Figure 3: Hierarchical clustering analysis (method=ward, distance=Euclidian) of the pattern of PFCAs formed upon oxidation (i.e., $\triangle$ PFCA) in each sample.

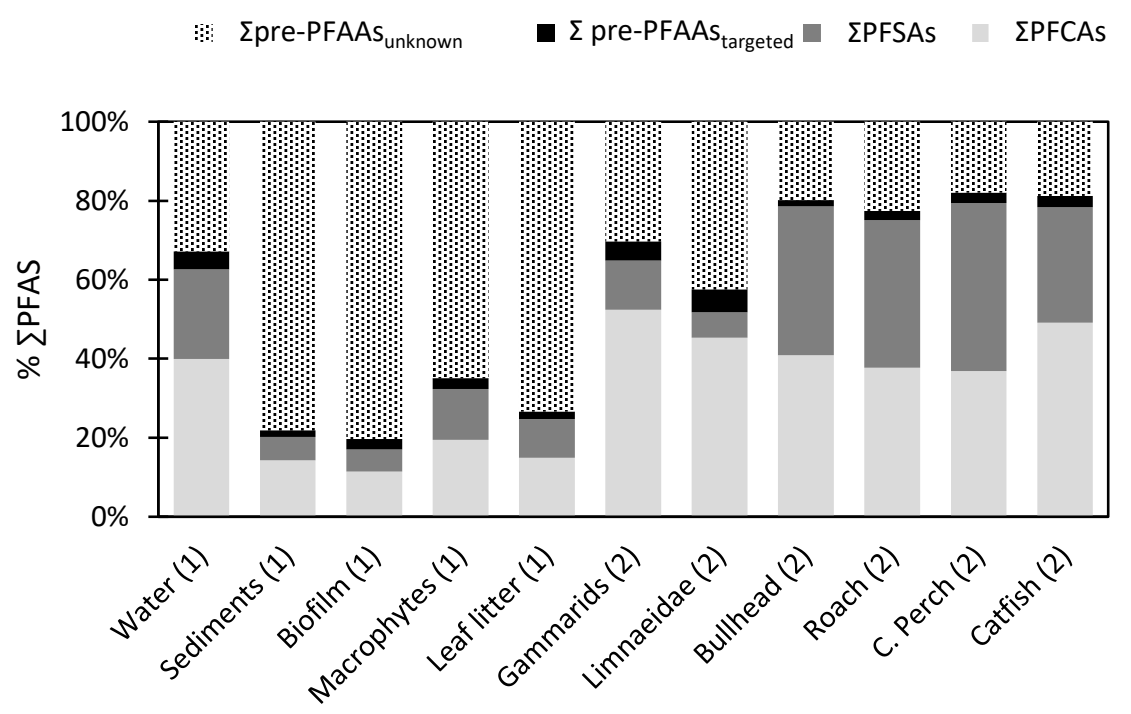

Figure 4: Relative contribution of pre-PFAAs unknown, pre-PFAAstargeted, PFSAs and PFCAs to ¿PFASs (expressed on a molar basis) in the trophic web of the Orge River. The number of replicates is indicated between brackets. 